\title{
INFORMAÇÃO E CONHECIMENTO NO CAMPO CIENTÍFICO DA CIÊNCIA DA INFORMAÇÃO
}

\author{
Roberia de Lourdes de Vasconcelos Andrade \\ Mestra em Ciência da Informação \\ Professora do Curso de Biblioteconomia \\ Universidade Federal de Alagoas \\ roberiabiblio@gmail.com \\ Edilson Targino de Melo Filho \\ Mestre em Ciência da Informação \\ Professor do Curso de Biblioteconomia \\ Universidade Federal da Paraíba \\ edilsondmelo@gmail.com \\ Wendia Oliveira de Andrade \\ Mestra em Ciência da Informação \\ Professora do Curso de Arquivologia \\ Universidade Estadual da Paraíba \\ wendia2810@hotmail.com
}

\begin{abstract}
Resumo Informação e todos os aspectos cognitivos que ela também detém enquanto ciência.

Palavras-chave

Ciência da Informação. Conhecimento. Informação. Reflexões conceituais.
\end{abstract}

A Ciência da Informação apresenta-se interdisciplinar, permitindo a interação com outras áreas do saber. Este artigo propõe uma reflexão acerca da relação significativa das conceituações no campo da Ciência da Informação, em específico sobre informação, conhecimento, memória entre outros conceitos. A pesquisa foi estruturada a partir de reflexões sobre o tema, com base em uma pesquisa bibliográfica. Neste ensaio foram selecionadas algumas conceituações, que nos levam a refletir sobre a questão históricoepistemológica da informação relacionada ao conhecimento e também à memória, sendo esta a premissa maior do estudo. Faz parte destas discussões as inter-relações conceituais, em que é possível relacioná-las a partir do que nos apresentam autores que contribuíram não apenas com a formulação de conceitos, mas para todo um construto de significados. Por fim, consideramos que estas definições encontradas têm uma perspectiva bastante filosófica, o que não nos impede de vislumbrar uma relação com a Ciência da

\section{CONTEXTUALIZAÇÃO}

A presente discussão reflete sobre conceitos fartamente encontrados na literatura que fundamenta a Ciência da Informação. Partindo de uma perspectiva filosófica, fizemos uso de autores que contribuíram, e ainda o fazem, com conceituações e explanações acerca da informação, conhecimento e memória.

A necessidade de expor as ideias aqui apresentadas surgiu a partir das leituras e discussões no âmbito da Ciência da Informação, que nasceram quase que naturalmente. Os questionamentos suscitados pelas digressões expressas por estes autores conduziram à inferências acerca do que nos era apresentado e passível de utilização, fosse de maneira teórico-reflexiva ou mesmo metodologicamente em pesquisas na área da Ciência da Informação.

Não é tarefa fácil dissertar acerca de trabalhos tão complexos e de cunho filosófico, em sua maioria, porém além de ser um grande 
exercício cognitivo também o é para nosso intelecto. Para tanto fizemos uso dos conceitos e definições mais relevantes, em nossa concepção, apresentadas por autores como Jacob Bronowski, Ernst Cassirer, Marshall Sablins, Jiri Zeman, Tefko Saracevic e Leila Maria Serafim Pacheco.

As ideias propostas por esses autores evidenciaram uma abordagem conceitual necessária à discussão sobre a temática da informação e do conhecimento enquanto possibilidades de constituição de uma relação significativa. Da mesma forma que a análise e construção dos conceitos proporcionaram uma categorização epistemológica no que se refere aos termos informação, conhecimento, cultura e memória.

A partir do diálogo entre os conceitos podemos estabelecer as relações expostas e discutidas neste ensaio. Então, fica claro que há várias possibilidades de inter-relação conceitual entre os termos, sobretudo porque a Ciência da Informação tem $O$ viés interdisciplinar e permite o diálogo entre as disciplinas, entretanto é necessário expor a conexão teórica de maneira objetiva, se preocupando com as falácias que este processo pode produzir. Estas reflexões acerca de determinado construto teórico conceitual, podem auxiliar na melhoria ou adequação da ciência como um todo. Gasque (2007) fundamentado em May (2004) expõe que a ciência "tem a função de compreender e explicar, mesmo que provisoriamente, os fenômenos sociais e naturais, centrando-se em questões particulares e buscando desafiar crenças convencionais." Não é nossa pretensão fundamentar uma teoria ou qualquer outro tipo de procedimento que requer maiores aprofundamentos e propriedade enquanto cientistas, nosso objetivo é apenas expor nossas apreciações sobre conteúdos informacionais inter-relacionais como informação, conhecimento e memória, mas essencialmente tendo a Ciência da Informação como campo teórico-metodológico para eles.

\section{INFORMAÇÃO: CONCEITUAÇÕES EPISTEMOLÓGICAS NA CIÊNCIA}

A informação se apresenta como o grande insumo intelectual do novo século, visto que seu conceito, polissêmico, não transmite uma ressignificação dos conteúdos epistemológicos existentes, sempre direcionando a outros conceitos. Nesta perspectiva, a informação se condensa em vários aspectos que depende, impreterivelmente, de seu contexto. Então, definir informação é algo que vai além de elencar características e aspectos a serem observados. Torna-se necessário entender que tal conceituação é a que mais se adequa ao que se propõe, seja com uma pesquisa a ser realizada ou qualquer outro trabalho que necessite de tal exposição.

A Ciência da Informação tem sua gênese em um movimento contradisciplinar amplo, em resposta as várias conjecturas da ciência moderna, e em um processo que se deu como resposta ao caos documental (SOUZA, 2008). É importante frisar que esse contexto pressupõe uma análise do objeto de estudo da Ciência da Informação, que é a informação. Entretanto, essa informação que é passível de significação está envolvida num contexto interdisciplinar, fundamentado na ampla relação das práticas dos profissionais envolvidas com esse processo.

O ambiente informacional permite a tessitura de uma rede conceitual que evoca uma prática e uma reflexão substancial das relações conceituais estabelecidas. Diante desta premissa, o ordenamento de elementos, materiais ou não, permite a classificação de tal forma que a informação absoluta não cresce e nem se perde, ela se divide para poder buscar sua disseminação, contudo este processo é intrínseco à organização da informação, no que concerne aos processos de tratamento e arranjo documental (entendido aqui como o suporte material) e o informacional.

É evidente que o crescimento exponencial das tecnologias proporcionou um avanço no número de informações, representando também uma maior preocupação com a organização e classificação da informação. Se pudermos perceber ou 
conceber a informação como artefato, é igualmente possível entendê-la como bem cultural. A informação pode ser entendida como "todo bem que constitua um testemunho material dotado de valor de civilização" (ZANIRATO; RIBEIRO, 2006, p. 257), ou ainda conforme Pacheco (1995, p. 21) "um monumento, um objeto, uma música etc., que caracteriza a cultura da qual é proveniente". Assim sendo, Popper (1972 apud PACHECO, 1995, p. 21) corrobora com a máxima de que informação é um bem cultural, um artefato.

Dado o seu exponencial crescimento, sobretudo, a partir do final do século XIX a informação passou a ser entendida, na visão de Pacheco (1995, p. 23) como uma "alienação do cérebro e consequentemente da memória", isto significa que entender a informação como um artefato é saber que ela pode ser utilizada num contexto distinto daquele para o qual e no qual foi produzida, ressaltando que a informação pode ser considerada dinâmica, devido a sua rápida atualização, acesso e uso.

Destarte, Le Coadic (2004, p. 5) chama de artefato, todo documento "que representa ou expressa um objeto, uma ideia ou uma informação por meio de signos gráficos e icônicos (palavras, imagens, diagramas, mapas, figuras, símbolos), sonoros e visuais" independentemente do suporte ser em papel ou eletrônico.

Pacheco (1995, p. 22) nos coloca que essa explosão informacional está "suplantando a memória", ou seja, o artefato informação não é mais armazenado no cérebro humano como antes, mas sim em "armazéns especialmente criados para ela".

Para Zeman (1970, p. 157) a informação significa ordenar alguma coisa, significa a classificação de alguma coisa "a informação é, pois, a qualidade da realidade material de ser organizada". A informação só vai existir no espaço, no tempo, no movimento, ela é estruturada e só vai existir materializada; deixando claro que a materialidade não é algo físico, mas é tudo aquilo que é percebido pelos sentidos.

Saracevic (1996, p. 43) afirma que "problemas informacionais existem há longo tempo, sempre estiveram mais ou menos presentes" e tratar de definir informação não se configura fora deste processo informacional.

No entendimento de Crippa (2010, p. 2) a informação é concebida como "um conjunto de dados organizados a partir de princípios ordenadores e classificatórios, através de práticas que atuam com base nas necessidades informacionais ligadas a configurações históricas da sociedade". Portanto, a informação se caracteriza pelo seu contexto multidisciplinar configurado a partir das estruturas pré-conceituais estabelecidas na dinâmica da experiência humana em contato com a sociedade.

É bem verdade que na Ciência da Informação seu objeto de estudo, a informação, é concebido como uma espécie de representação, tendo em vista que a representação do conhecimento é premissa fundamental para apropriação da informação, assim como González de Gomes (1993, p. 217) preconizava a necessidade de recontextualizar as fontes e canais de informação:

[...] a busca de uma informação que seja uma resposta pertinente $\mathrm{e}$ relevante às nossas perguntas requer a reconstrução de um complexo cenário onde sejam agregadas as populações de fontes e canais de informação, de modo a permitir processos seletivos, organizados $\mathrm{e}$ econômicos de busca e recuperação.

Sendo assim, a informação passa a ser uma representação do conhecimento. E como tal pode ser reafirmada no seu contexto, através das condições epistemológicas que são postas para sua consolidação enquanto objeto de estudo da Ciência da Informação.

\section{INFORMAÇÃO, CONHECIMENTO, CULTURA E MEMÓRIA: inter-relação de conceitos}

A teoria marxista impulsionou o mundo a observar as forças que influenciavam seu desenvolvimento, sobretudo as que impactavam em seus modelos de produção. Neste aspecto, as relações desse processo imbricaram em linguagens que desempenham 
papéis importantes na representação da informação, algo que está, essencialmente, ligado aos aspectos culturais.

Assim sendo a "cultura está relacionada, na sua especificidade, a uma lógica dominante - a lógica objetiva da superioridade prática ou a lógica significativa no esquema conceitual" (SAHLINS, 2003, p. 61), pois estes aspectos culturais da sociedade estão envolvidos no processo de significação específico, estruturado e baseado nas relações conceituais estabelecidas na conjunção dos elementos "conhecimento, imaginação, cultura e memória".

O conhecimento é uma construção mental, onde o seu termo designa tanto a coisa conhecida quanto $\mathrm{O}$ ato de conhecer (subjetivo) e o fato de conhecer. Neste sentido, o pensamento possui um papel importante no processo de conhecer, pois há um pleno domínio no manejo dos conteúdos empíricos (CASSIRER, 1986), determinando o esclarecimento acerca das atividades informacionais expostas ou propostas. Cassirer (1986) ainda argumenta sobre o conhecimento adquirido de maneira ingênua, pois quando ele é elevado à consciência torna-se, simplesmente, a reprodução de uma realidade por si só existente, ordenada, estruturada e dessa forma, a atividade reflexiva limita-se a um ato de repetição.

O conhecimento provém da informação de maneira similar como a informação provém de dados. O conhecimento de acordo com Davenport e Prusak (1998, p. 6) pode ser entendido como:

[...] uma mistura fluida de experiência condensada, valores, informação contextual e insight experimentado, a qual proporciona uma estrutura para a avaliação e incorporação de novas experiências e informações. Ele tem origem e é aplicado na mente dos conhecedores.

Certamente, Ernst Cassirer estava certo ao atrelar os fundamentos do conhecimento científico aos primórdios da modernidade, sobretudo porque nessa época foi quando começou a se consolidar e estruturar a ciência como um todo.
Los conceptos fundamentales del conocimiento científico, los conceptos de fuerza y causa, de substancia y materia, tienen todos una larga y complicada prehistoria metafísica, que se remonta mucho más allá de los comienzos de la época moderna (CASSIRER, 1986, p. 22, grifo nosso).

Ademais, tendo em vista que a "informação não existe fora do tempo, ela transporta-se e conserva-se no tempo" (ZEMAN, 1970, p. 162), o conhecimento é também responsável pela elucidação dos conteúdos epistemológicos ressaltados ao longo do tempo, sua definição é tão polissêmica quanto à de informação. Entretanto, parece estar claro que a reflexão filosófica acerca do conhecimento se faz necessária para o exercício da consciência no que tange aos aspectos informacionais. Referenciando tal contexto, os sujeitos possuem aptidões especiais, como a capacidade de exercitar o conhecimento e a imaginação. De acordo com Bronowski (1997, p. 11) a palavra imaginação "deriva da criação de imagens na mente, a partir do que Wordsworth chamou de olho interior". Para o autor as atividades intelectuais do homem estão sempre condicionadas ao olho, dessa forma, o que chamamos e entendemos como livre arbítrio é a visualização de alternativas e a capacidade de escolhas. Para o autor, "as nossas capacidades, quanto às formas de memória e de imaginação, de simbolismo e de símbolo, estão todas condicionadas à visão" (BRONOWSKI, 1997, p. 16). Contudo, não é apenas o cérebro que faz inferências do mundo, o olho também; este sentido da visão vai além de enxergar, mas compreende vários aspectos filosóficos constitutivos da memória e do conhecimento.

A Ciência da Informação se coloca como responsável pela reflexão teórica no que diz respeito aos processos intrínsecos relacionados à informação (seleção, organização e disseminação) e como tal é capaz de apresentar procedimentos teóricometodológicos que culminam na guarda de memória, tanto no campo humanista quanto no campo científico. Mais do que a descrição de procedimentos técnicos que facilmente 
encontramos em outros campos, como a Biblioteconomia, por exemplo. A Ciência da Informação vai além das questões práticas que envolvem a informação, trata de como ela se relaciona com seus usuários informacionais, como ela é percebida, interpretada e compreendida.

No final do século XX, com o surgimento das Tecnologias de Informação e Comunicação, os profissionais da informação se voltam para o imenso volume de informações que era produzido, mas principalmente para a sua guarda e recuperação. Em sentido amplo a memória passou a ser analisada enquanto fenômeno social, o que Oliveira e Rodrigues (2008, p. 4) vão denominar de "produto das relações sociais estabelecidas pelos homens." Essas relações sociais são caracterizadas pelas ações dos sujeitos no que diz respeito à materialização da informação.

Assim sendo, a memória é entendida por Azevedo Netto (2008, p. 12) como um "conjunto de eventos, fatos, personagens que, através da existência no passado, possuem experiências consistentes para o estabelecimento de uma relação da atualidade e o seu passado, quer imediato, quer remoto".

Já Oliveira e Rodrigues (2008, p. 3) compreendem a memória como "a capacidade humana de reter fatos e experiências do passado e retransmiti-los às novas gerações através de diferentes registros, graças a um conjunto de funções psíquicas".

Para Dodebei (2010, p. 14) a memória pode ser compreendida sob uma "dimensão cultural [que] abarca fronteiras de outras disciplinas que têm o passado como material de estudo, como a História, a Arqueologia, a Ciência da Informação".

O ponto convergente nas definições é, certamente, a compreensão da memória sob um aspecto da interação humana com seu passado. Essa convergência permite entender que a relação entre informação, conhecimento, cultura e memória é mais amplo do que se pensa. Ela perpassa as barreiras físicas e conceituais, pois está alicerçada nos campos estruturais do que venha a se definir como informação, conhecimento, cultura e memória.

\section{PERSPECTIVAS CONCEITUAIS E COMO RELACIONAM-SE COM A CIÊNCIA DA INFORMAÇÃO}

Não é exaustivo afirmar que a Ciência da Informação é um campo interdisciplinar (SARACEVIC, 1996) e que por natureza conceitual pode se relacionar com diversos campos. Entretanto, ao se colocar como uma ciência pós-moderna a Ciência da Informação se ver obrigada a interagir constantemente com as configurações discursivas da ciência moderna (CRIPPA, 2010).

Há uma gama de definições tanto de informação quanto da Ciência da Informação, como facilmente podemos constatar no trabalho de Rafael Capurro e Birger Hjorland (2007, p. 149). O conceito de informação, onde afirmam que para "uma ciência como a Ciência da Informação, é sem dúvida importante a forma como seus termos fundamentais são definidos e, assim como em outros campos, na Ciência da Informação a questão sobre como definir informação é frequentemente levantada."

Conforme o exposto, as definições sobre determinada ciência são constantemente questionados, como se formaram, quais os mais importantes e o que considerar ao analisar teoricamente o que nos é apresentado. Certamente a Ciência da Informação tem características de vários campos do conhecimento devido essencialmente a sua formação constituída de "engenheiros, bibliotecários, químicos, lingüistas, filósofos, psicólogos, matemáticos, cientistas da computação, homens de negócios" entre outros, como assevera com propriedade Saracevic (1996, p. 48, grifo nosso).

$\mathrm{Na}$ perspectiva da Ciência da Informação, a informação para Le Coadic (2004, p. 4-5) é um "conhecimento inscrito (registrado) em forma escrita (impressa ou digital), oral ou audiovisual, em um suporte" e o objetivo da informação "permanece sendo a apreensão de sentidos ou seres em sua significação, ou seja, continua sendo o conhecimento".

Considerando que as perspectivas conceituais da Ciência da Informação estão 
enraizadas ao processo de crescimento documental e as suas peculiaridades no que tange a recuperação e representação da informação, é preciso destacar que ainda há uma ausência de estudos, na Ciência da Informação, que evidenciem os aspectos teórico-metodológicos e as resultantes acerca dessas reflexões.

Entretanto, várias facetas complementam os conteúdos interdisciplinares que se relacionam no seu cerne, assim como Souza e Dias (2011, p. 53) alertam para o informacionalismo, que corresponde a uma prática científica essencialmente social:

A prática científica é essencialmente uma prática social e, nesse sentido, é condicionada pelos modos de produção capitalista e de desenvolvimento atualmente vigentes. Considerando-se que este corresponde ao informacionalismo, o pensamento informacional tangencia as práticas nos diversos setores da sociedade, notadamente, técnico-científico; ou, pelo menos, encontra-se nelas presentes (SOUZA; DIAS, 2011, p. 53, grifo do autor).

É evidente que as práticas sociais estão entrelaçadas à prática científica, tendo em vista que os cientistas são seres sociais e vivem em sociedade. Tais práticas estão inseridas no contexto científico, produzindo conhecimento e corroborando com o desenvolvimento da ciência como um todo.

\section{CONSIDERAÇÕES FINAIS}

A Ciência da Informação adquiriu perspectiva multidisciplinar. Tal premissa conduziu a uma inquietação: por que não histórica? Já que provém ricamente de tantas definições, conceitos e caracterizações?
A perspectiva considerada neste ensaio se apresenta num contexto em que a Ciência da Informação permeia todos os campos citados ao longo deste percurso constitutivo, pois seu objeto de estudo é a informação, que está ligada ao conhecimento, à memória e à cultura, cada uma com suas especificidades, mas podendo ser relacionadas com base no pilar da informação, seja ela compreendida ora objetiva ora subjetivamente.

Portanto, para Galvão e Borges (2000, p. 48) a Ciência da Informação se caracteriza "pelo estudo da informação, pelo relacionamento com várias ciências e insere-se no contexto da sociedade, tendo aqui o profissional da informação um papel importante e necessário".

É nesta confluência de ideias que o conhecimento vai elaborando e ganhando forma na consciência, assim como destaca Barreto (2011, p. 56) "o pensamento se faz informação e a informação se faz conhecimento". Contudo, vale salientar que a força do pensamento produz atritos necessários para a construção do que venha a se transformar em conhecimento, evidentemente que esse processo é subsidiado pelos conteúdos informacionais inerentes à representação do conhecimento.

Aqui destacamos quatro conteúdos importantes para esse processo: informação, conhecimento, cultura e memória. Certamente, não é demasiado destacar que esses conceitos são provenientes das relações sociais estabelecidas pelos sujeitos na sociedade, e, portanto terão significações distintas e adequadas às suas atribuições informacionais a que se apliquem, tanto semanticamente quanto de forma a representar a informação.

\title{
INFORMATION AND KNOWLEDGE IN THE SCIENTIFIC FIELD OF INFORMATION SCIENCE
}

\begin{abstract}
Information Science is presented as a interdisciplinary area, permitting its integration with other areas of knowledge. The present article intends to propose a reflection about the significant relation of conceptualizations in the field of Information Science, specifically about information, knowledge and memory, among other concepts. The research was structured from the
\end{abstract}


Roberia de Lourdes de Vasconcelos Andrade / Edilson Targino de Melo Filho / Wendia Oliveira de Andrade

reflections about the theme, based on a bibliographic research. In this essay, there were selected some conceptualizations which leads to a reflection about the historical and epistemological question of information related to knowledge and to memory too, and this is the greatest premise of the study. It is part of these discussions the conceptual inter-relations, in which is possible to relate them from what is presented by authors who contributed not only with the formulation of concepts, but also with all a construct of meanings. Finally, it is considered that these found definitions have a perspective too much philosophic, what does not impede to visualize a relation with Information Science and all the cognitive aspects that it also has while a science.

Keywords

Information Science. Knowledge. Information. Conceptual reflections. Artigo recebido em 04/08/2014 e aceito para publicação em 29/09/2014

\section{REFERÊNCIAS}

AZEVEDO NETTO, Carlos Xavier de. Preservação do patrimônio arqueológico: reflexões através do registro e transferência da informação. Ciência da Informação, Brasília, v. 37, n. 3, p. 7-17, set./dez. 2008.

BARRETO, Aldo de Albuquerque. Transferência da informação para o conhecimento. In: AQUINO, Mirian de Albuquerque $(\mathrm{Org})$. O campo da Ciência da Informação. João Pessoa: Editora Universitária, 2011. p. 49- 56.

BORKO, H. Information science: what is it? American Documentation, v. 19, n.1, 1968.

BRONOWSKI, Jacob. As origens do conhecimento e da imaginação. Brasília: UNB, 1997.

CAPURRO, Rafael; HJORLAND, Birger. O conceito de informação. Tradução de Ana Maria Pereira Cardoso; Maria da Glória A. Ferreira; Marco Antônio de Azevedo.

Perspectivas em Ciência da Informação, Belo Horizonte, v. 12, n. 1, p. 148 - 207, jan./abr. 2007.

CASSIRER, Ernst. El problema del conocimiento en la filosofia y en la ciencia modernas. Tradução de Wenceslao Roces. Cidade do México: Fondo de Cultura Económica: 1986.

CRIPPA, Giulia. Entre ciência e humanidades: o problema da ordem da memória da/para a ciência da informação. In: ENCONTRO NACIONAL DE PESQUISA EM CIÊNCIA
DA INFORMAÇÃO, 11., 2010, Rio de Janeiro. Anais... Rio de Janeiro: ANCIB, 2010.

DAVENPORT, Thomas H; PRUSAK, Laurence. Conhecimento Empresarial. Rio de Janeiro: Ed. Campus, 1998.

DODEBEI, Vera Lucia Doyle Louzada de Mattos. Informação, memória, conhecimento: convergência de campos conceituais. In: ENCONTRO NACIONAL DE PESQUISA EM CIÊNCIA DA INFORMAÇÃO, 11., 2010, Rio de Janeiro. Anais... Rio de Janeiro: ANCIB, 2010.

GALVÃO, Maria Cristiane Barbosa; BORGES, Paulo César Rodrigues. Ciência da informação: ciência recursiva no contexto da sociedade da informação. Ciência da Informação, Brasília, v. 29, n.3, p. 40-49, 2000 .

GASQUE, Kelley Cristine Gonçalves Dias. Teoria Fundamentada: nova perspectiva à pesquisa exploratória. In: MUELLER, Suzana Pinheiro. (Org.). Métodos para a pesquisa em Ciência da Informação. Brasília: Thesaurus, 2007.

GONZÁLEZ DE GOMEZ, Maria Nélida. A representação do conhecimento e o conhecimento da representação: algumas questões epistemológicas. Ciência da Informação, Brasília, v. 22, n. 3, p. 217-222, set./dez. 1993.

Le COADIC, Yves-François. A ciência da informação.Tradução de Maria Yêda F. S. de Filgueiras Gomes. 2. ed. rev. e atual. Brasília, DF: Briquet de Lemos/Livros, 2004. 124 p. 
OLIVEIRA, Eliane Braga de; RODRIGUES, Georgete Medleg. As concepções de memória na Ciência da Informação no Brasil: estudo preliminar sobre a ocorrência do tema na produção científica. In: ENCONTRO NACIONAL DE PESQUISA EM CIÊNCIA DA INFORMAÇÃO, 9., 2008, São Paulo. Anais... São Paulo: USP/ANCIB, 2008.

PACHECO, Leila Maria Serafim. A informação enquanto artefato. Informare: Caderno Programa de Pós-Graduação, Rio de Janeiro, v. 1, n. 1, p. 20-24, jan./jun. 1995.

\section{SAHLINS, Marshall. Cultura e Razão}

Prática. Rio de Janeiro: Zahar, 2003.

SOUZA, Edivanio Duarte de. Dimensões teórico-metodológicas da Ciência da Informação: dos desafios à consolidação Epistemológica. In: ENCONTRO NACIONAL DE PESQUISA EM CIÊNCIA DA INFORMAÇÃO, 9., 2008, São Paulo. Anais... São Paulo: USP/ANCIB, 2008.
SOUZA, Edivanio Duarte de; DIAS, Eduardo José Wense. A integração disciplinar na ciência da informação: os não-ditos sobre essa familiar desconhecida. Ciência da Informação, Brasília, v. 40, n.1, jan./abr. 2011.

ZANIRATO, Silvia Helena; RIBEIRO, Wagner Costa. Patrimônio cultural: uma Percepção da Natureza Como hum Bem nao Renovável . Rev. Bras. Hist. [online]., v.26, n.51, p. 251-262, 2006. Disponível em: $<$ http://www.scielo.br/pdf/rbh/v26n51/12.p df $>$. Acesso em: 28 jul. 2014.

ZEMAN, Jiri. Significado filosófico da noção de informação. In: ROYAUMONT, Cahiers de. O conceito de informação na Ciência contemporânea. Tradução de Maria Helena Kuhner. São Paulo: Paz e Terra, [1970]. (Série Ciência e Informação, v. 2, p. 154-179). 